\title{
Structural insights into dissimilatory sulfite reductases: structure of desulforubidin from Desulfomicrobium
}

\section{norvegicum}

\author{
Tânia F. Oliveiraa, ${ }^{1,2}$ Edward Franklin' ${ }^{2}$, José P. Afonso ${ }^{3}$, Amir R. Khan $^{2}$, Neil J. Oldham $^{3}$, Inês A. C. Pereira ${ }^{*}$ and \\ Margarida Archer ${ }^{*}$.
}

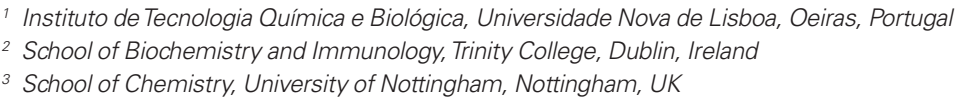

Edited by:

Martin G. Klotz, University of Louisville, USA

\section{Reviewed by:}

John Robert Cort, Pacific Northwest National Laboratory, USA

Vilmos Fulop, University of Warwick, UK

\section{${ }^{*}$ Correspondence:}

Margarida Archer, Membrane Protein Crystallography Laboratory, Instituto de Tecnologia Química e Biológica,

Universidade Nova de Lisboa, Avenida da República EAN, 2780-157 Oeiras,

Portugal.

e-mail:archer@itqb.unl.pt

Inês A. C. Pereira, Bacterial Energy

Metabolism Laboratory, Instituto de Tecnologia Química e Biológica,

Universidade Nova de Lisboa, Avenida da República EAN, 2780-157 Oeiras,

Portugal.

e-mail: ipereira@itqb.unl.pt
Dissimilatory sulfite reductases (dSiRs) are crucial enzymes in bacterial sulfur-based energy metabolism, which are likely to have been present in some of the earliest life forms on Earth. Several classes of dSiRs have been proposed on the basis of different biochemical and spectroscopic properties, but it is not clear whether this corresponds to actual physiological or structural differences. Here, we describe the first structure of a dSiR from the desulforubidin class isolated from Desulfomicrobium norvegicum. The desulforubidin (Drub) structure is assembled as $\alpha_{2} \beta_{2} \gamma_{2}$, in which two DsrC proteins are bound to the core $[D s r A]_{2}[D s r B]_{2}$ unit, as reported for the desulfoviridin (Dvir) structure from Desulfovibrio vulgaris. Unlike Dvir, four sirohemes and eight [4Fe-4S] clusters are present in Drub. However, the structure indicates that only two of the Drub coupled siroheme-[4Fe-4S] cofactors are catalytically active. Mass spectrometry studies of purified Drub and Dvir show that both proteins present different oligomeric complex forms that bind two, one, or no DsrC proteins, providing an explanation for conflicting spectroscopic and biochemical results in the literature, and further indicating that $\mathrm{DsrC}$ is not a subunit of $\mathrm{dSiR}$, but rather a protein with which it interacts.

Keywords: sulfite reductases, sulfur metabolism, sulfate reducing bacteria, siroheme, iron-sulfur clusters, $\mathrm{X}$-ray structure

\section{INTRODUCTION}

Microorganisms play an important role in sulfur transformations and are a critical component of sulfur cycling on our planet. Many Bacteria and Archaea have the ability to use sulfur compounds in a series of oxidation or reduction reactions, thereby generating metabolic energy in the process of dissimilatory metabolism. Data from isotopic analysis suggests that dissimilatory reduction of sulfur compounds is an extremely ancient process which began 3.5 billion years ago (Canfield and Raiswell, 1999; Canfield et al., 2006). After sulfate concentrations increased significantly in the Precambrian oceans approximately 2.5 billion years ago, reduction of sulfate also became of global significance (Canfield et al., 2006). A key enzyme in the reduction of sulfate/sulfite is the dissimilatory sulfite reductase ( $\mathrm{dSiR})$, which is responsible for the six electron reduction of sulfite to sulfide. dSiRs belong to a redox enzyme super family, characterized by the presence of a coupled siroheme- $[4 \mathrm{Fe}-4 \mathrm{~S}]$ cluster cofactor, which include assimilatory sulfite (aSiRs) and nitrite reductases, and other types of sulfite reductases (Crane and Getzoff, 1996; Dhillon et al., 2005; Loy et al., 2007). The dSiR is composed of two subunits, DsrA and DsrB, in a $\sim 200 \mathrm{kDa} \alpha_{2} \beta_{2}$ arrangement. The $d s r A$ and $d s r B$ genes are paralogous and probably originated from duplication of an early $d s r$ gene before the separation of the Archaea and Bacteria domains (Dahl et al., 1993; Molitor et al., 1998; Wagner et al., 1998). aSiRs, which generate sulfide for incorporation into aminoacids and cofactors, are monomeric enzymes with an internal twofold symmetry of a unit related to DsrA/DsrB, which suggests gene duplication, followed by gene fusion of an ancestral sulfite reductase gene present in a very early life form (Crane et al., 1995, 1996; Dhillon et al., 2005). After the early divergence of the aSiR and $\mathrm{dSiR}$ genes there was incorporation of a ferredoxin domain in the $d s r$ gene before separation into the $d s r A$ and $d s r B$ genes (Dahl et al., 1993). Evolutionary analysis of the $d s r A B$ genes indicates they were mainly inherited via vertical transmission, except for a few events of lateral gene transfer, namely in the archaeal genus Archaeoglobus, which has $d s r A B$ genes of bacterial origin, in the thermophilic genus Thermodesulfobacterium, and Gram-positive bacteria of the Firmicutes phylum like Desulfotomaculum species (Wagner et al., 1998; Klein et al., 2001; Zverlov et al., 2005; Loy et al., 2007). In contrast to aSiRs, which reduce sulfite directly to sulfide, the in vitro product of dSiRs is not only sulfide, but a mixture of products including also trithionate and thiosulfate (Peck and LeGall 1982), suggesting other proteins may be required for the complete reduction to sulfide. Thus, the mechanism and physiological products of dissimilatory reduction by $\mathrm{dSiRs}$ is still a matter of debate. 
Biochemical studies of dSiRs led to their categorization into four different classes based on UV/visible absorption and other molecular characteristics (Rabus et al., 2007): Desulfoviridin (Dvir), a green protein (characteristic absorption peak at $628 \mathrm{~nm}$ ) present in Desulfovibrio spp. (Lee and Peck, 1971; Moura et al., 1988; Pierik and Hagen, 1991; Steuber et al., 1994; Wolfe et al., 1994); Desulforubidin (Drub), a reddish-brown protein (characteristic absorption peak at $545 \mathrm{~nm}$ ) present in Desulfomicrobium and Desulfosarcina spp. (Lee et al., 1973; Moura et al., 1988; Arendsen et al., 1993; DerVartanian, 1994); Desulfofuscidin (characteristic absorption peak at $576 \mathrm{~nm}$ ) present in Thermodesulfobacterium spp. (Hatchikian and Zeikus, 1983; Hatchikian, 1994); and the brown colored P-582 protein (characteristic absorption peak at $582 \mathrm{~nm}$ ) present in Desulfotomaculum spp. (Akagi et al., 1974). All these dSiRs are proposed to assemble as $\alpha_{2} \beta_{2}$, but the type and content of the cofactors has been the subject of some controversy (Rabus et al., 2007).

After many years of failed attempts, the first X-ray structures of dSiRs were determined, including the Dvir from Desulfovibrio vulgaris Hildenborough at $2.10 \AA$ (Oliveira et al., 2008a), and dSiR from Archaeoglobus fulgidus at $2.04 \AA$ resolution (Schiffer et al., 2008), showing an $\alpha_{2} \beta_{2}$ arrangement with similar overall folds, and finally shedding light on the cofactor composition of these proteins. Four sirohemes and eight $[4 \mathrm{Fe}-4 \mathrm{~S}]$ clusters are present in A. fulgidus $\mathrm{dSiR}$, whereas two sirohemes, two sirohydrochlorins (the metal-free form of siroheme), and eight [4Fe-4S] clusters are present in D. vulgaris Dvir. Nevertheless, only two sirohemes per $\alpha_{2} \beta_{2}$ unit are proposed to be catalytically active in both proteins. The sequence-based predictions of a similar fold to aSiRs, and of a separate ferredoxin domain containing a [4Fe-4S] cluster that transfers electrons to the active site, were confirmed by these structures. In addition, the crystal structure of D. vulgaris Dvir provided important functional information, because it comprised the DsrAB subunits complexed with the DsrC protein in a $\alpha_{2} \beta_{2} \gamma_{2}$ arrangement. DsrC was originally thought to constitute a third subunit of dSiR (Pierik et al., 1992), but has subsequently been recognized as an independent protein that interacts with DsrAB (Steuber et al., 1995; Cort et al., 2001, 2008; Dahl et al., 2005; Mander et al., 2005; Pires et al., 2006), and is homologous to the TusE protein involved in biosynthetic sulfur-relay reactions (Ikeuchi et al., 2006; Numata et al., 2006). In the structure of the D. vulgaris DsrAB-DsrC complex, the strictly conserved Cys at the C-terminus of DsrC is positioned right next to the substratebinding site pointing to the involvement of DsrC in the reduction of sulfite (Oliveira et al., 2008a).

More recently, the crystal structure of the Dvir from Desulfovibrio gigas has been reported in two active forms (Dvir-I and Dvir-II; Hsieh et al., 2010), also including the DsrAB and DsrC proteins. The overall structure of the two D. gigas Dvir forms are very similar to D. vulgaris Dvir, and the C-terminal tail of DrsC from both forms is either inserted into the channel formed between DsrA and DsrB or swung away from the catalytic siroheme (Hsieh et al., 2010). D. gigas Dvir belongs to the Dvir class, and comprises eight iron-sulfur clusters, two sirohemes, and two sirohydrochlorins, as reported for Dvir. However, Dsr-II contains a $[3 \mathrm{Fe}-4 \mathrm{~S}]$ cluster associated with the siroheme instead of the usual $[4 \mathrm{Fe}-4 \mathrm{~S}]$ center, observed in all the other structures analyzed so far. Additionally, the A. fulgidus DsrAB structure has been characterized in complex with several ligands (Parey et al., 2010).

In this work we report the 3D structure of a dSir from a different class, the Drub isolated from Desulfomicrobium norvegicum, at $2.5 \AA$ resolution. Moreover, we report mass spectrometry studies of both Drub and Dvir that provide important insights into the quaternary structures of these proteins in solution.

\section{MATERIALS AND METHODS PROTEIN PURIFICATION}

Desulfomicrobium norvegicum (formerly known as Desulfovibrio desulfuricans strain Norway 4 and Desulfovibrio baculatus strain Norway 4) was grown in lactate/sulfate medium and cell extracts prepared as previously described (Pereira et al., 2006). The purification protocol was performed aerobically at $6^{\circ} \mathrm{C}$. The soluble fraction was loaded on a DEAE-Sepharose fast flow XK50/30 column (GE Healthcare) equilibrated with $20 \mathrm{mM}$ Tris- $\mathrm{HCl} \mathrm{pH} 7.6$ buffer. A stepwise gradient of increasing $\mathrm{NaCl}$ concentration (0 to $1 \mathrm{M}$, incremental steps of $0.05 \mathrm{M}$ ) was performed. The fraction eluted with $300 \mathrm{mM} \mathrm{NaCl}$ was dialyzed against $20 \mathrm{mM}$ Tris- $\mathrm{HCl} \mathrm{pH}$ 7.6. The protein was then concentrated and loaded onto a Q-Sepharose 26/10 ion-exchange column (GE Healthcare), and a similar procedure was performed. The protein sample was then subjected to size exclusion chromatography on a Sephacryl S-200 HR (GE Healthcare). Finally, the protein was dialyzed in $20 \mathrm{mM}$ Tris- $\mathrm{HCl}$ pH 7.6 and loaded onto a Mono Q 5/50 GL column (GE Healthcare) and eluted using the same $\mathrm{NaCl}$ step gradient as outlined above. All purification steps were monitored by Sodium Dodecyl Sulfate Polyacrylamide Gel Electrophoresis (SDS-PAGE) and UV-visible spectroscopy analysis.

\section{CRYSTALLIZATION}

The protein was concentrated with Amicon ( $100 \mathrm{kDa}$ cutoff) to $8 \mathrm{mg} \mathrm{ml}^{-1}$ in $20 \mathrm{mM}$ Tris- $\mathrm{HCl} \mathrm{pH} 7.6$ and was further used for crystallization trials with a TTP LabTech's mosquito nanoliter pipetting crystallization robot. Many screens were tested (PEG I and II from Qiagen; Structure Screen, Pact Premier I and II, and JSCG from Molecular Dimensions; Wizard I and II and JBS screen HTS L I and II from Jena Biosciences) with some initial crystals being obtained. Crystal optimization was complicated due to poor crystal reproducibility between different batches of purified protein, and protein degradation over time. Thin needle crystals were obtained using the hanging drop vapor diffusion method at $291 \mathrm{~K}$ with a reservoir volume of $500 \mu \mathrm{l}$ of 20\% PEG 3350 (w/v), 0.1 M BisTris Propane pH 7.5, and $0.2 \mathrm{M}$ $\mathrm{K} / \mathrm{Na}$ Tartrate. Crystals grew using a protein: precipitant ratio of $2: 1$ (total volume of $3 \mu \mathrm{l}$ ) over 2 months with dimensions of $0.15 \mathrm{~mm} \times 0.03 \mathrm{~mm} \times 0.03 \mathrm{~mm}$. Prior to X-ray data collection, crystals were cryo-protected by being briefly dipped into a reservoir solution supplemented with $25 \%$ glycerol, and immediately flash-cooled in liquid nitrogen.

\section{DATA COLLECTION AND STRUCTURE DETERMINATION}

$\mathrm{X}$-ray diffraction data were collected at $0.933 \AA$ at ID14-2 beamline, ESRF - Grenoble, France, to $2.5 \AA$ resolution. A total of 340 images were measured with an oscillation range of $0.6^{\circ}$ and exposure time 
of $10 \mathrm{~s}$ per image. Data were processed with MOSFLM (Leslie, 1992); and scaled with SCALA from the CCP4 program suite (Collaborative Computational project, Number 4, 1994). The sequence information for $D$. norvegicum $d s r A B$ genes is incomplete at their termini. They do however share $99 \%$ sequence identity with the corresponding genes of Desulfomicrobium baculatum (strain DSM 4028). This high identity allowed completion of the Drub $d s r A B$ sequences based on those from D. baculatum: 62 amino-acid residues were added at the $\mathrm{N}$-terminus of DsrA and 115 residues at the C-terminus of DsrB.

Molecular Replacement was done with PHASER (McCoy et al., 2007) using the D. vulgaris Dvir (PDB code: 2V4J; Oliveira et al., 2008a) as a search model. One PHASER run was performed searching independently for two molecules of each Dsr-A, B, and C subunits. A solution was obtained with rotation (RFZ) and translation functions (TFZ) of 22.9 and 23.1, respectively, and a refinement log-likelihood gain LLG of 662.90.

A first model building cycle was performed with BUCANEER (Cowtan, 2006). Electron-density map inspection and manual model building were carried out using COOT (Emsley and Cowtan, 2004). Further refinement was done with REFMAC5 (Murshudov et al., 1997) within the CCP4 program suite. For the refinement a subset $(5 \%)$ of the reflections were randomly excluded for cross validation $\left(R_{\text {free }}\right.$ calculation). All structural figures were drawn with PyMOL (DeLano, 2002).

The atomic coordinates and structure factors of Drub isolated from D. norvegicum were deposited in the RCSB Protein Data Bank with accession number $2 \mathrm{XSJ}$.

\section{MASS SPECTROMETRY STUDIES}

Purified D. norvegicum Drub and D. vulgaris Dvir were subjected to preparative $9 \%$ native gel electrophoresis. Each band was excised from the gel and the protein extracted by electro-elution as described in (Oliveira et al., 2008b). Nanoflow electrospray ionization-mass spectrometry was performed on the proteins thus obtained. Experiments were conducted on a Waters Synapt High Definition Mass Spectrometer (Manchester, UK) - a hybrid quadrupole/ion mobility/orthogonal acceleration time of flight (oa-TOF) instrument - equipped with a nanospray source and operated in TOF mode. Protein samples were buffer-exchanged into $1 \mathrm{M}$ ammonium acetate $\mathrm{pH} 7.5$ buffer using Vivaspin 500 centrifugal filters with $10 \mathrm{kDa}$ molecular weight cutoff (Sartorius, Göttingen, Germany), diluted to a final concentration of $5 \mu \mathrm{M}$ and electrosprayed from thin wall Nanoflow Probe Tips (Waters, Manchester, UK). Experiments were conducted at a capillary voltage of $1.5 \mathrm{kV}$, nanoflow gas pressure of $0.3 \mathrm{Bar}$, source temperature of $323 \mathrm{~K}$, and sample cone voltage of $30 \mathrm{~V}$, with the source operating in positive ion mode. Backing pressure was maintained between 5.0 and $6.0 \mathrm{mBar}$ to provide collisional cooling of ions in the intermediated vacuum region of the instrument. The collisional energies were $50-70 \mathrm{~V}$ in the trap and $30-50 \mathrm{~V}$ in the transfer, with a trap gas flow of $10 \mathrm{ml} \mathrm{min} \mathrm{m}^{-1}$ resulting in a pressure of $5.2 \times 10^{-2} \mathrm{mBar}$. Tandem mass spectrometry experiments were performed with trap voltages between 60 and $120 \mathrm{~V}$. The oaTOF-MS was operated over the scanning range of m/z 500-15000. Spectra were acquired and processed using Masslynx 4.1 software (Waters, Manchester, UK).

\section{ELECTRON TRANSFER ASSAYS}

Desulfoviridin from D. vulgaris Hildenborough was used in experiments to test potential electron donors, since it can be purified with much higher yields than Drub from D. norvegicum. Direct protein-protein interactions were probed using the surface plasmon resonance technique (Biacore T100 GE Healthcare). Two possible electron donors were tested: ferredoxin-I (FDX; DVU3276) isolated from D. vulgaris Hildenborough, and pyruvate-ferredoxin oxidoreductase (PFOR) isolated from Desulfovibrio africanus (as the D. vulgaris one is very unstable and shows $69 / 82 \%$ sequence identity/ homology with $D$. vulgaris protein). A CM5 (carboxymethylated dextran) chip from GE Healthcare was used for the immobilization of $\mathrm{dSiR}$ D. vulgaris, and FDX and PFOR were tested as analytes. In one of the cases, the reverse experiment was performed, with FDX being coupled to the CM5 chip and D. vulgaris $\mathrm{d} S i R$ used as analyte.

Reduction of sulfite by Dvir with pyruvate/PFOR as electron donors was followed by spectroscopic measurement of hydrogen sulfide, using an adaptation of the methylene blue (MB) method (Fogo and Milton, 1949). MB is produced when sulfide reacts with $N, N^{\prime}$-dimethyl-p-phenylenediamine (DPD) and ferric chloride under acidic conditions. For the assay, the reaction mixture contained $10 \mathrm{mM}$ sodium pyruvate, $100 \mu \mathrm{M}$ coenzyme A, $22.5 \mathrm{nM}$ PFOR, $625 \mathrm{nM}$ Dvir, and $200 \mu \mathrm{M}$ sodium sulfite in a total volume of $200 \mu \mathrm{l}$ and was started with the addition of sulfite and stopped at various time points ( $30 \mathrm{~min}, 1 \mathrm{~h}, 2 \mathrm{~h}, 3 \mathrm{~h}, 4 \mathrm{~h}$, and $12 \mathrm{~h}$ ) on addition of $50 \mu \mathrm{l}$ of the $\mathrm{DPD} / \mathrm{FeCl}_{3}$ mixture (prepared in $50 \% \mathrm{HCl}$ ). The color was allowed to develop by incubating at room temperature for $10 \mathrm{~min}$ before the absorbance was measured at $670 \mathrm{~nm}$ in a 96 well plate on a SpectraMax Plus384 spectrophotometer.

\section{RESULTS AND DISCUSSION DRUB CRYSTAL STRUCTURE}

The purified sample of $D$. norvegicum Drub showed three bands in SDS-PAGE analysis corresponding to DsrA, DsrB, and DsrC protein, as also reported for other dSiRs (Pierik et al., 1992; Steuber et al., 1995). Crystals of Drub were obtained using PEG3350 as precipitant ( $\mathrm{pH} \sim 7.5)$ and diffracted to $\sim 2.5 \AA$ at a synchrotron source. Drub crystals belonged to the orthorhombic space group $\left(\mathrm{P} 22_{1} 2_{1}\right)$ with unit cell dimensions $a=99.3, b=135.1$, and $c=178.0 \AA$. The Matthews coefficient (Matthews, 1968) was $2.7 \AA^{3} \mathrm{Da}^{-1}$, consistent with the presence of one molecule $\left(\alpha_{2} \beta_{2} \gamma_{2}\right)$ in the asymmetric unit and $53.3 \%$ of solvent content. The structure of Drub was determined by molecular replacement using the coordinates of $D$. vulgaris Dvir as search model.

The final crystallographic model of Drub comprised 1850 amino-acid residues out of 1856,4 sirohemes and 8 [4Fe-4S] clusters, 2 sulfite ions, 1 glycerol, and 1051 water molecules (Figure 1). Final refinement values for $R$ and $R_{\text {free }}$ are 15.6 and $20.8 \%$, respectively, with the entire model fitting the generally well defined electron-density map.

The deposited sequences for $D$. norvegicum $d s r A$ and $d s r B$ genes are incomplete at the $\mathrm{N}$-terminal of $d s r A$ and C-terminal of $d s r B$. However, due to the very high sequence identity ( $99 \%)$ with $D$. baculatum $d s r A B$ genes, the sequences of $D$. norvegicum $d s r A$ and $d s r B$ were completed. On inspection of the inserted residues extrapolated from the sequence of $D$. baculatum, six residues were observed which did not fit the electron-density and thus were not 
conserved in the D. norvegicum sequences. Amino-acid residues at positions $33 \mathrm{~A}, 57 \mathrm{~A}$, and 59A were refined manually with serine providing the best fit, residue 35A was refined as Gln, 323B as Ser and $364 \mathrm{~B}$ as Ile, taking also into account their chemical environments. These predictions are expected to be robust, but nevertheless potential mis-assignments will not have major implications for the structural model due to the nature and position of these residues. Structure analysis and validation of the model was achieved using PROCHECK (Laskowski et al., 1993) from CCP4 indicating good stereochemistry. The relevant statistics for data processing and structure refinement are displayed in Table $\mathbf{1 .}$

\section{OVERALL DRUB ARCHITECTURE AND COFACTORS}

The overall structure of D. norvegicum Drub (Figure 1) forms a dimer of $\alpha \beta \gamma$ units with a MW of $200 \mathrm{kDa}$. The $\alpha_{2} \beta_{2} \gamma_{2}$ unit corresponding to [DsrA $]_{2}[\mathrm{DsrB}]_{2}[\mathrm{DsrC}]_{2}$ is composed of the $\alpha$ subunit comprising residues $2-437$ of chains $A$ and $D$, the $\beta$ subunit consisting of residues $2-386$ from chains B and E, and the $\gamma$ subunit containing residues $2-105$ of chains $\mathrm{C}$ and $\mathrm{F}$. In some dSiRs, namely Dvirs, the small DsrC protein copurifies with DsrAB (Pierik et al., 1992; Steuber et al., 1995), whereas in other dSiRs it does not (Dahl et al., 1993; Molitor et al., 1998).

The C-terminal arm of DsrA (405-437 of chains A/D) extends toward DsrB from the other monomer (DsrB*, chains E/B), and establishes several hydrogen-bonds with amino-acid residues from this subunit, important for dimer stabilization. Both DsrA and DsrB proteins are formed by three domains $\left(\mathrm{A}_{1} \mathrm{~A}_{2} \mathrm{~A}_{3} / \mathrm{B}_{1} \mathrm{~B}_{2} \mathrm{~B}_{3}\right)$ as observed in D. vulgaris (Oliveira et al., 2008a), A. fulgidus (Schiffer et al., 2008), and D. gigas (Hsieh et al., 2010) dSiRs. The Drub structure comprises a conserved four domain core $\left(A_{1} A_{2} B_{1} B_{2}\right.$, where $\mathrm{A}_{1}$ corresponds to residues $19 \mathrm{~A}-168 \mathrm{~A}, \mathrm{~A}_{2}$ to $169 \mathrm{~A}-241 \mathrm{~A}$ and $135 \mathrm{~B}-207 \mathrm{~B}, \mathrm{~B}_{1}$ to residues $24 \mathrm{~B}-134 \mathrm{~B}$, and $\mathrm{B}_{2}$ to residues $323 \mathrm{~A}-402 \mathrm{~A}$ and $283 \mathrm{~B}-370 \mathrm{~B})$ that is homologous to the structures of aSiRs and aNiR (Crane et al., 1995; Schnell et al., 2005; Swamy et al., 2005).

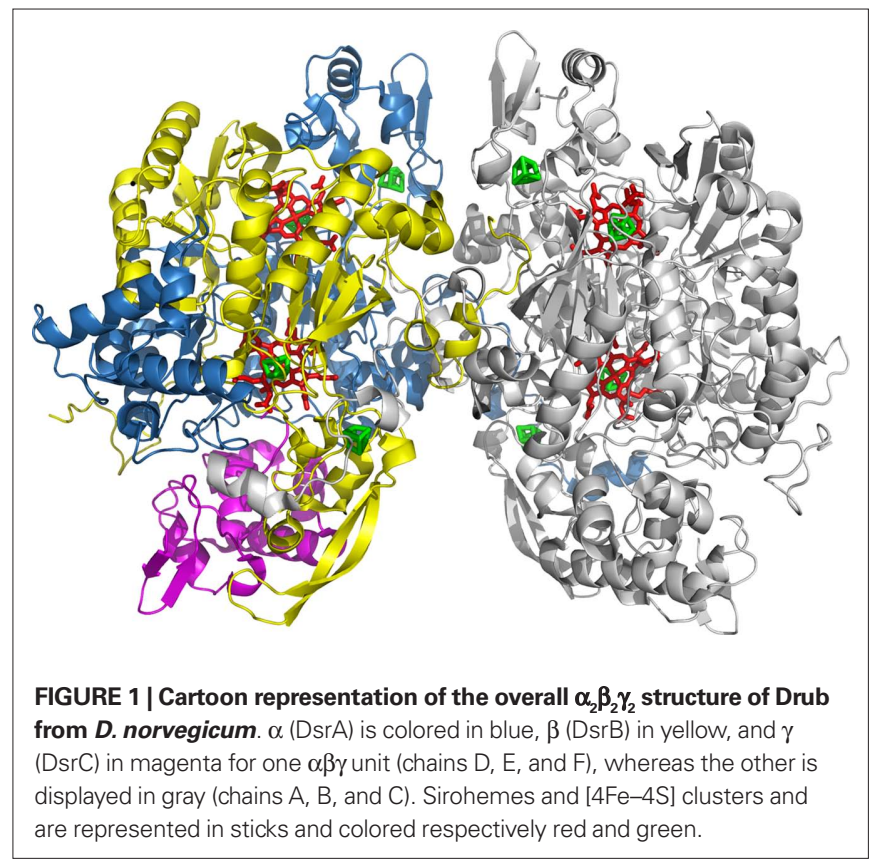

A third ferredoxin domain $\mathrm{A}_{3} / \mathrm{B}_{3}$ is present in both DsrA and DsrB, where $\mathrm{A}_{3}$ consists of residues $242 \mathrm{~A}-322 \mathrm{~A}$, and $\mathrm{B}_{3}$ refers to residues 208B-282B.

\section{Table 1 | Data collection and refinement statistics.}

\begin{tabular}{|c|c|}
\hline \multicolumn{2}{|l|}{ Data collection and processing } \\
\hline Beamline & ID14-2 ESRF, Grenoble \\
\hline Wavelength $(\AA ̊)$ & 0.933 \\
\hline Resolution range $(\AA ̊)$ & $45.10-2.53(2.67-2.53)$ \\
\hline No of images & 340 \\
\hline Space group & $\mathrm{P} 2,2_{1} 2_{1}$ \\
\hline Unit cell parameters $(\AA ̊)$ & $a=99.3, b=135.1, c=178.0$ \\
\hline Mosaicity $\left(^{\circ}\right)$ & 0.4 \\
\hline No. of complexes in asymmetric unit & $1\left(\alpha_{2} \beta_{2} \gamma_{2}\right)$ \\
\hline$R_{\text {merge }}(\%)^{\mathrm{a}}$ & $11.4(28.6)$ \\
\hline$R_{\text {pim }}(\%)^{b}$ & $4.2(11.1)$ \\
\hline$I / \sigma(\Lambda)$ & $12.8(5.8)$ \\
\hline Multiplicity & $8.1(7.4)$ \\
\hline Completeness (\%) & $99.4(96.9)$ \\
\hline Total reflections & 649457 (82716) \\
\hline Unique reflections & 79925 (11215) \\
\hline Wilson B $\left(\AA^{2}\right)$ & 33.5 \\
\hline \multicolumn{2}{|l|}{ Refinement } \\
\hline No. of amino-acid residues & 1850 \\
\hline \multicolumn{2}{|l|}{ Other molecules } \\
\hline Siroheme (SRM) & 4 \\
\hline$[4 \mathrm{Fe}-4 \mathrm{~S}]$ & 8 \\
\hline $\mathrm{SO}_{3}^{2-}$ & 2 \\
\hline Glycerol & 1 \\
\hline Water molecules & 1051 \\
\hline$R$ (working set) (\%) & 15.6 \\
\hline$R_{\text {free }}(\%)$ & 20.8 \\
\hline \multicolumn{2}{|l|}{ Ramachandran plot, residues in } \\
\hline Most favored regions (\%) & 88.5 \\
\hline Additional allowed regions (\%) & 11.0 \\
\hline Generously allowed regions (\%) & 0.3 \\
\hline Disallowed regions (\%) & 0.3 \\
\hline \multicolumn{2}{|l|}{ Average B-factor $\left(\AA^{2}\right)$} \\
\hline \multicolumn{2}{|l|}{ Main chain } \\
\hline DsrAB & 13.6 \\
\hline DsrC & 26.7 \\
\hline \multicolumn{2}{|l|}{ Side-chain } \\
\hline DsrAB & 14.9 \\
\hline DsrC & 28.7 \\
\hline Solvent molecules & 18.0 \\
\hline \multicolumn{2}{|l|}{ r.m.s. deviation from ideal values } \\
\hline Bond length $(\AA ̊)$ & 0.015 \\
\hline Bond angle $\left({ }^{\circ}\right)$ & 1.56 \\
\hline
\end{tabular}

Values in parentheses are for the outer shell.

(a) $R_{\text {merge }}=\sum_{\mathrm{hkl}} \sum_{i}\left|l_{i}(\mathrm{hkl})-\overline{l(\mathrm{hkl})}\right| / \sum_{\mathrm{hk}} \sum_{i} l_{i}(\mathrm{hkl})$

(b) $R_{\text {pim }}=\sum_{\text {hkl }}[1 /(\mathrm{N}-1)]^{1 / 2} \sum_{\mathrm{i}}\left|l_{i}(\mathrm{hkl})-\overline{I(\mathrm{hkl})}\right| / \sum_{\mathrm{hkl}} \sum_{\mathrm{i}} l_{i}(\mathrm{hkl})$

Calculated with the program SCALA, $R_{\text {merge }}$ and $R_{\text {pim }}$ are indicators of the precision of the final merged and averaged data-set, where $l_{i}($ hkl) is the observed intensity of the ith measurement, $\overline{l(h k l)}$ is the average intensity of multiple observations of symmetry-related reflections and $N$ is redundancy. 
Each of the $\mathrm{A}_{2} / \mathrm{B}_{2}$ domains binds a saddle-shaped siroheme[4Fe-4S] cofactor, giving a total of four sirohemes per $\alpha_{2} \beta_{2}$ unit as described for the $\mathrm{dSiR}$ of $A$. fulgidus (Figure 2). In contrast, dSiRs from D. vulgaris and D. gigas contain two sirohemes and two flat sirohydrochlorins per $\alpha_{2} \beta_{2}$ unit. The [4Fe-4S] cluster of the coupled siroheme cofactor in $\mathrm{A}_{2}$ is coordinated by the strictly conserved Cys- $\mathrm{X}_{5}$-Cys- $\mathrm{X}_{\mathrm{n}}$-Cys- $\mathrm{X}_{3}$-Cys motif (Cys residues 177A, $183 \mathrm{~A}, 221 \mathrm{~A}$, and 225A), whereas a different cysteine motif (C-X $\mathrm{C}-\mathrm{C}-\mathrm{X}_{3}-\mathrm{C}$ ) is observed in the $\mathrm{B}_{2}$ domain (Cys residues $151 \mathrm{~B}, 188 \mathrm{~B}$, $189 \mathrm{~B}$, and 193B). In each motif two cysteine residues (225A and $193 \mathrm{~B})$ share the coordination of the $[4 \mathrm{Fe}-4 \mathrm{~S}]$ cluster and the siroheme. In the $\mathrm{A}_{3} / \mathrm{B}_{3}$ ferredoxin domains the $[4 \mathrm{Fe}-4 \mathrm{~S}]$ cluster is coordinated by cysteines 283A, 303A, 306A, and 309A; and 231B, 263B, 266B, and 269B, respectively. Previous cofactor quantifications of $\mathrm{dSiRs}$ from the Drub class indicated a content of $2.2 \pm 0.3 \mathrm{~mol}$ of siroheme and $21 \pm 2 \mathrm{~mol}$ of iron per mol of D. baculatum Drub (Moura et al., 1988), and 2 sirohemes and approximately 15 irons for Desulfosarcina variabilis Drub (Arendsen et al., 1993). The present structure indicates these values were underestimated with a total of 4 sirohemes, 36 irons, and 32 sulfurs present in the $D$. norvegicum Drub $\alpha_{2} \beta_{2}$ unit.

The structure of DsrC is mainly helical and comprises 104 residues out of 105. The C-terminal arm of DsrC (Leu98C-Val105C) is inserted into a cleft between DsrA and DsrB, which leads into the active site, with the conserved terminal cysteine (S $\gamma$ Cys104C/E) covalently linked to the catalytic siroheme $\left(20^{\prime}\right.$-meso carbon of the porphyrin ring; Figure 2). This covalent interaction was also observed in D. vulgaris (Oliveira et al., 2008a) and more recently in D. gigas Dvirs (Hsieh et al., 2010). We proposed that the covalent Cys104C-siroheme bond is non-physiological and forms as a result of porphyrin oxidation to give a $\pi$-cation radical that is quenched by the nearby Cys (Oliveira et al., 2008a). The presence of this bond probably stabilizes the DsrAB-DsrC complex and facilitates crystallization.

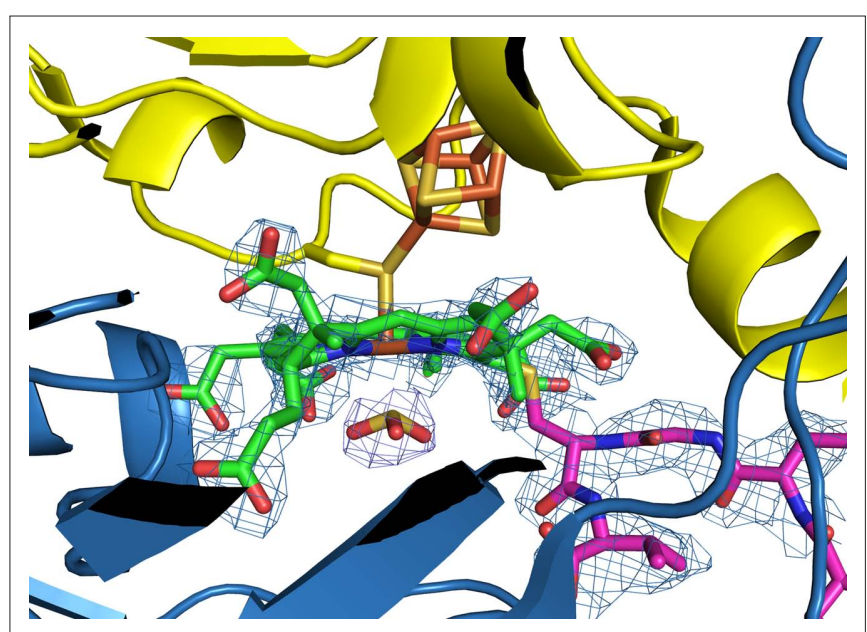

FIGURE 2 | Zoomed view of siroheme B - [4Fe-4S] cluster bridged by a cysteine residue (Cys193B). The covalent bond between Cys104C (DrsC is magenta) and siroheme $\mathrm{B}$ is displayed. $\mathrm{A} \mathrm{SO}_{3}^{2-}$ is observed at the distal site of the catalytic siroheme. The $2 \mathrm{Fo}-\mathrm{Fc}$ electron-density map is contoured at $1.5 \sigma$ DsrA is displayed in blue and DsrB in yellow. Atom color code: $\mathrm{C}$, green; $\mathrm{N}$, blue; Fe, orange; $\mathrm{S}$, gold, and $\mathrm{O}$, red.
Interestingly, two other DsrC conformations are observed in the recently reported $D$. gigas Dvir structure: in one there is no covalent bond between Cys104C and the siroheme and the cysteine sidechain is closer to the sulfite present in the active site; in the other one, the DsrC C-terminal arm is swung away from the siroheme in a way that brings Cys104C close to Cys93C (3.4-4.0 ^ apart), but not forming a disulfide bond (Hsieh et al., 2010). In 70\% of the molecules the DsrC arm is in the extended configuration, and in $30 \%$ in the retracted one, but both conformations are proposed to be in dynamic equilibrium (Hsieh et al., 2010). Previous crystal and solution structures of isolated DsrC proteins have also shown flexibility around the C-terminal tail, with either extended or retracted conformations (Cort et al., 2001, 2008; Weiss et al., 2004; Mander et al., 2005). Structural analysis of D. gigas Dvir reveals that Pro 101C suffers significant conformational changes between these two conformations, functioning as a hinge, and being responsible for the different positions of the C-terminal arm (Pro-Thr-Gly-Cys-Val). There is enough space around the C-terminal tail in the DsrAB cleft to accommodate such structural rearrangements, while the rest of the DsrC globular domain and the DsrAB structure remain basically the same regardless of the DsrC C-terminal segment conformation. The presence of these two alternative conformations of the DsrC arm in the D. gigas Dvir structure provide supporting evidence for our proposal that the DsrC penultimate Cys is involved in the catalytic cycle and that a disulfide bond is ultimately formed between the two conserved DsrC cysteines (Oliveira et al., 2008a).

\section{THE CATALYTIC SITE}

The catalytic siroheme-bound by DsrB is buried in the protein interior and sits at the interface between DsrA and DsrB (Figure 2). DsrA provides the basic residues for substrate-binding at the distal site, whereas DrsB supplies the residues at the proximal site including Cys193B. This cysteine residue is covalently bound to the siroheme iron $(-2.3 \AA)$ and a cluster iron $(-2.5 \AA)$, where both irons are $c a$. $4.3 \AA$ apart. The $[4 \mathrm{Fe}-4 \mathrm{~S}]$ cluster is bound exclusively by residues from DsrB subunit. A blob of electron-density with a trigonal pyramidal shape is observed at the distal site of the siroheme iron suggesting an axial ligand bound to it. A sulfite ion $\left(\mathrm{SO}_{3}^{2-}\right)$ was modeled into the blob with its sulfur pointing toward the siroheme moiety (sulfur atom is at a distance of $\sim 2.3 \AA$ to the siroheme iron, Figure 2). Arg101A, Arg172A, Lys213A, and Lys215A are strictly conserved residues that interact directly with the substrate. These residues together with other basic residues, such as arginines (83A, 231A, 376A, 378A, and $71 \mathrm{~B})$, lysine $217 \mathrm{~A}$, and histidines (150B and $152 \mathrm{~B}$ ) form a positively charged pocket with a favorable environment for binding the negatively charged sulfite and compensate the negative charges of the siroheme carboxylate groups (propionates and acetates substituents). The identification of the substrate channel leading to the catalytic siroheme is not consensual. A 15- $\AA$ long channel was identified in A. fulgidus dSiR (DsrAB), involving Arg80A, Arg358A, His64A, and His $141 \mathrm{~B}$, with a size of $10 \times 15 \AA$ at its entrance and $c a 6 \times 9 \AA$ at its substrate-binding pocket (Schiffer et al., 2008), This large cavity is however almost completely occupied by the C-terminal arm of DsrC, which is not present in A. fulgidus $\mathrm{dSiR}$. Beside this channel, a narrower funnel is observed in Drub with a positive electrostatic potential which makes the distal side of the catalytic siroheme solvent accessible. The entrance is formed by Tyr212A, Arg376A, Glu381A 
Leu226B, and is not blocked by the DsrC binding. This putative substrate funnel is also present in the other dSiR structures. In $D$. gigas Dvir, two other possible entry points are proposed: channel A, where Lys100C can bind a sulfite at the surface and transfer it to the active site through a swing of the DsrC C-terminal arm; and channel $\mathrm{B}$ which can connect the sirohydrochlorin and siroheme within each monomer, with Cys198B and Arg231A located in the middle of the channel (Hsieh et al., 2010). More structural and functional information is needed to clarify this issue.

Despite the presence of four siroheme-[4Fe-4S] cofactors in Drub, the sirohemes bound by DsrA should not be catalytically active, because they are not solvent accessible, and several basic residues important for substrate-binding are missing at the distal side of the heme. D. vulgaris and D. gigas Dvirs contain sirohydrochlorin at this site in DsrA, whereas A. fulgidus also has a siroheme. Interestingly, in aSiRs this second cofactor-binding site is empty.

\section{STRUCTURAL COMPARISON OF DRUB WITH OTHERS dSiRs}

Superposition of Drub with other dSiR structures from D. vulgaris, D. gigas, and A. fulgidus with PDBeFold (Krissinel and Henrick, 2004) yielded root-mean-square (r.m.s.) deviations of $0.74,0.8$, and $1.37 \AA$ for 1830,1837 , and 1500 aligned $\mathrm{C} \alpha$ atoms, respectively. Drub shares 74,72 , and $53 \%$ of amino-acid sequence identity with D. vulgaris, D. gigas, and A. fulgidus dSiRs, respectively.

Although the overall fold of dSiRs is quite conserved, there are some relevant localized differences (Figure 3). In Drub, DsrB has an inserted loop formed by residues 239B and 254B (5 residues longer than in D. vulgaris and D. gigas Dvirs, and 11 residues longer than A. fulgidus $\mathrm{dSiR}$ ), which corresponds to a longer two stranded anti-parallel $\beta$-sheet followed by a three-residue-H-bonded turn. This loop extends outward in between the N-terminal of DsrA* (chain D) and DsrC. Moreover, the DsrB N-terminus of Drub is 11-residues longer than in A. fulgidus $\mathrm{dSiR}$, but similar to D. vulgaris and D. gigas Dvir. It adopts an extended conformation toward DsrA residues: 39A-41A (located in a bending loop, e.g., the distance between the $\mathrm{C} \alpha$ s of $3 \mathrm{~B}-41 \mathrm{~A}$ is $5.9 \AA$ ), and $147 \mathrm{~A}-151 \mathrm{~A}$ (sited in a $\alpha$-helix, C $\alpha$ distance of $6 \mathrm{~B}-151 \mathrm{~A}$ is $5.3 \AA$ ); and $\mathrm{DsrC}$ (e.g., O atom of Pro10B is $5.9 \AA$ apart from Oe1 Glu35C, $C \gamma$ of Pro13B is $4.7 \AA$ away from $\mathrm{C} \alpha$ Gly38C). The $\mathrm{O}$ atom of Val4B and Asn $16 \mathrm{~B}$ are establishing hydrogen-bonds with the side-chain atoms of $\operatorname{Arg} 125 \mathrm{~A}$ and His158A, respectively. Interestingly, both of these inserted segments, not present in A. fulgidus dSiR, are flanking DsrC in Drub, D. vulgaris and D. gigas Dvir (Figure 3), and may play a role in the interaction between DsrAB and DsrC in these proteins.

In Drub, D. vulgaris and D.gigas Dvir, DsrA shows a 16-residueinsertion (257A-274A), which is partially overlapped by a five-residue longer loop in A. fulgidus (119B-125B: A. fulgidus numbering). In spite of similar length, the C-terminus of DsrA of both Drub and Dvirs show a different conformation compared to A. fulgidus dSiR. In Drub the DsrA C-terminal arm extends along DsrB* (chain E, e.g., distances between $\mathrm{C} \alpha$ atoms: $404 \mathrm{~A}-378 \mathrm{E}$ is $4.0 \AA, 414 \mathrm{~A}-264 \mathrm{E}$ is 4.9 $\AA, 435 \mathrm{~A}-86 \mathrm{D}$ is $5.4 \AA$ ) until it reaches DsrA* (chain D) and close to DsrC* (chain F), whereas in A. fulgidus the C-terminal arm is more "wrapped" around itself and only in closer contact with DsrB*. These C-terminal tails start diverging after residue 420A (Drub numbering).

Although no 3D structure is yet available for dSiRs belonging to either Desulfofuscidin or P582 classes, we expect similar overall folds for these proteins based on the high sequence identity (ranging from $\sim 50$ to $70 \%$ ) and similarity (ranging from $\sim 65$ to $80 \%$ ) among them. $D$. norvegicum Drub shows highest sequence identity to $D$. vulgaris Dvir (73\%), followed by $\mathrm{P} 582$ proteins ( $65 \%)$, and lastly A. fulgidus $\mathrm{dSiR}$ and Desulfofuscidins ( $-50 \%)$. The DsrA and DsrB cysteine motifs

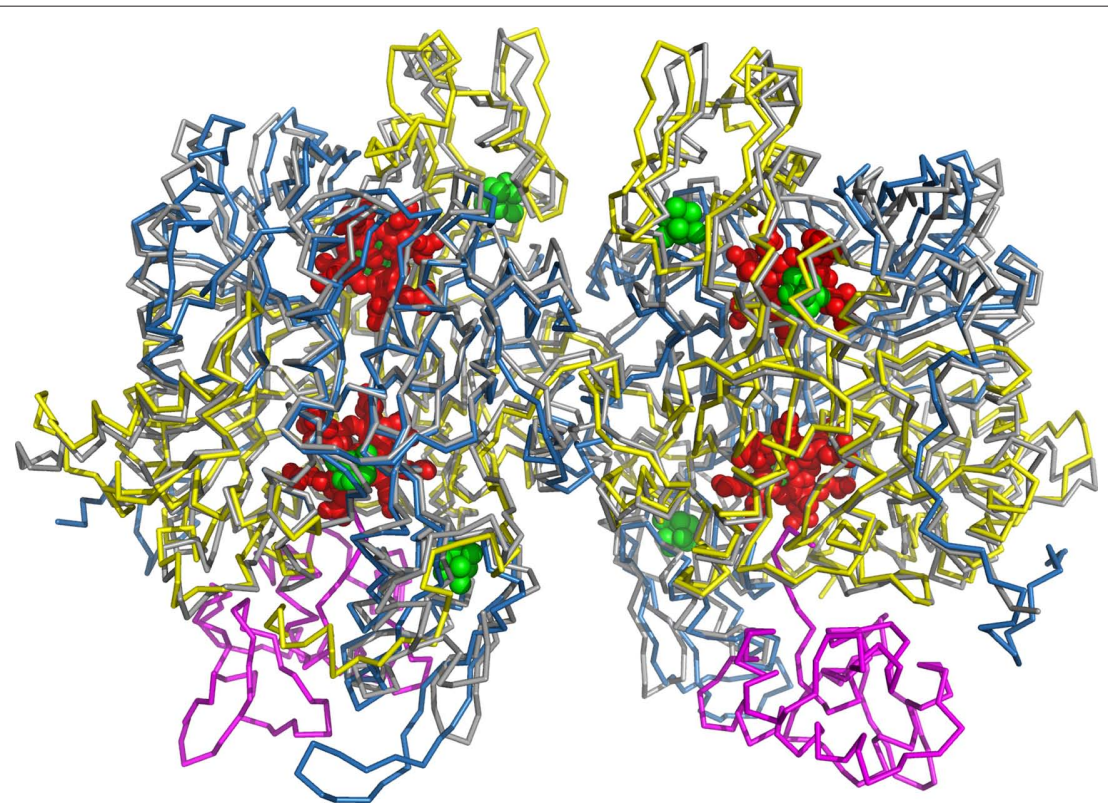

FIGURE 3 | C $\alpha$ superposition of D. norvegicum Drub (DrsA-yellow, DsrB-blue, and DsrC. magenta) and A. fulgidus dSiR (gray), structures. For sake of clarity and due to high homology with Drub, the structures of D. vulgaris and D. gigas Dvirs were not represented. Sirohemes (red) and [4Fe-4S] clusters (green) are drawn in cpk mode (spheres). 
required for binding the $[4 \mathrm{Fe}-4 \mathrm{~S}]$ cluster of the coupled cofactor, as well as the cysteine residues coordinating the ferredoxin domain $[4 \mathrm{Fe}-$ 4 S] cluster, are strictly conserved among the analyzed Desulfofuscidin or P582 dSiRs. In addition, most positively charged residues around the catalytic siroheme and surrounding the substrate channel are also conserved in these proteins. Furthermore, the non-conservation of some substrate interacting residues around the non-catalytic DsrA siroheme is also observed in the Desulfofuscidin or P582 dSiRs, which indicates that the presence of a single catalytically active siroheme is a shared characteristic of the different classes of dSirs.

\section{ANALYSIS OF D. VULGARIS AND D. NORVEGICUM dSIR OLIGOMERIC STATES}

As previously reported for D. vulgaris Dvir (Lee et al., 1973; Seki et al., 1979; Wolfe et al., 1994; Marritt and Hagen, 1996), as well as recently for D. gigas (Hsieh et al., 2010) we observed that purification of Dvir (Oliveira et al., 2008b) and Drub by ion-exchange chromatography originates two or three peaks that cannot be distinguished by several analytical techniques including SDS-PAGE, UV-Visible spectroscopy, and enzyme activity. However, they also originate distinct bands on native gel electrophoresis, which together with the separation by ion-exchange chromatography indicates that they have quite different isoelectric points (Oliveira et al., 2008b).

Native gel of the purified D. norvegicum Drub showed three distinct bands, indicating the protein is also present in different states (Figure 4B). In D. vulgaris Dvir only two bands were observed (Figure 4A; Seki et al., 1979; Oliveira et al., 2008b), and crystals could only be obtained from the faster migrating band 1 . In order to clarify the difference between the different forms, nanoflow electrospray ionization-mass spectrometry studies of the bands isolated from preparative native gel electrophoresis of $D$. vulgaris and $D$. norvegicum dSiRs were carried out.

The MS spectrum for D. vulgaris Dvir band 1 produced well defined peaks corresponding to a MW of $213.8 \mathrm{kDa}$, indicating the presence of a single species (Figure 5A). Analysis of Dvir band 2 from the same gel, provided less definition across the peaks, and a mixture of three species with MW of 213.4, 200.5, and 105.9 kDa

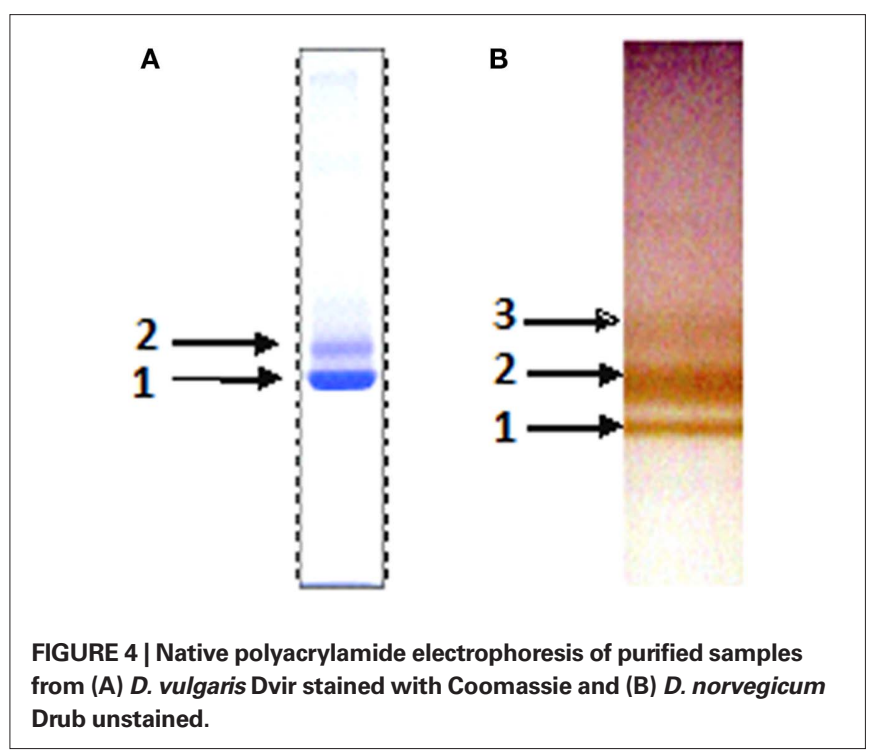

is observed (Figure 5B). Molecular weight calculations for the different possible stoichiometries between D. vulgaris DsrA, DsrB, and DsrC, including cofactors, gives a theoretical MW of $213.3 \mathrm{kDa}$ for the D. vulgaris $\alpha_{2} \beta_{2} \gamma_{2}$ form, $200.5 \mathrm{kDa}$ for $\alpha_{2} \beta_{2} \gamma$, and $106.6 \mathrm{kDa}$ for $\alpha \beta \gamma$ forms (Table 2). From these theoretical masses we can conclude that the fast migrating band 1 of Dvir comprises a single $\alpha_{2} \beta_{2} \gamma_{2}$ species, which is in agreement with the crystal structure obtained. In contrast, the slower migrating Dvir band 2 includes a mixture of three different forms, $\alpha_{2} \beta_{2} \gamma_{2}$ and $\alpha_{2} \beta_{2} \gamma$ and $\alpha \beta \gamma$.

For D. norvegicum Drub, bands 1 and 2 produced well defined peaks at 215.1 and $202.0 \mathrm{kDa}$, respectively, corresponding to single $\alpha_{2} \beta_{2} \gamma_{2}$ (band 1) and $\alpha_{2} \beta_{2} \gamma$ (band 2) forms (Figures 5C,D). In the slower migrating band 3 (Figure 5E), a mixture of peaks at 215.1, $202.3,189.1,107.2$, and $94.5 \mathrm{kDa}$ is observed, suggesting the presence of an heterogeneous sample corresponding to $\alpha_{2} \beta_{2} \gamma_{2}, \alpha_{2} \beta_{2} \gamma$, $\alpha_{2} \beta_{2}, \alpha \beta \gamma$, and $\alpha \beta$ complex compositions. Interestingly, in both Dvir and Drub the dissociation of DsrC is associated with loss of the corresponding siroheme.

Tandem MS experiments were then carried out to try to test dissociation of DsrC from DsrAB in the single species samples, by gradually increasing the trap voltage (Figure 6). At $60 \mathrm{~V}$ no dissociation is observed, whereas from 80 to $120 \mathrm{~V}$ we can detect dissociation of free DsrC, siroheme-bound DsrC as well as siroheme, from the $\alpha_{2} \beta_{2} \gamma_{2}$ and $\alpha_{2} \beta_{2} \gamma$ forms of Drub and the $\alpha_{2} \beta_{2} \gamma_{2}$ form of Dvir. The presence of DsrC ions without attached siroheme indicate sub-stoichiometric covalent bonding of this protein to the porphyrin, or disruption of the bond under conditions of collisional activation in the mass spectrometer.

These results are important because they clearly show that the purified dSiRs from D. vulgaris and D. norvegicum, which seem homogeneous by SDS-PAGE analysis, are in fact a mixture of oligomeric states, even after purification. A similar situation is likely to occur for other purified dSiRs described in the literature, which may explain the disparate results in terms of cofactor content and spectroscopic properties (Rabus et al., 2007), the appearance of several peaks with different pIs in ion-exchange chromatography, and also why this protein resisted attempts to crystallize for so long. The major species present in both Dvir and Drub are the $\alpha_{2} \beta_{2} \gamma_{2}$ and $\alpha_{2} \beta_{2} \gamma$ forms. These forms can be separated on ion-exchange chromatography, but the resulting fractions still have some of the other form, probably due to an equilibrium between dissociation and association of the DsrC protein. In addition, the MS results indicate that the crystallization process selects for the $\alpha_{2} \beta_{2} \gamma_{2}$ form with a covalent bond between DsrC and the siroheme, since other forms are present in the Drub protein solution used for crystallization. The presence of the covalent bond is likely to make the whole structure more stable and enable crystallization. Forms of the $\alpha_{2} \beta_{2} \gamma_{2}$ complex without a covalent bond are also likely to be present in the $D$. vulgaris Dvir solution, which did not crystallize. This was confirmed in the D. gigas Dvir X-ray structure where non-covalently bonded DsrC is observed, either in a stretched or retracted conformation (Hsieh et al., 2010). In this work the authors could crystallize two of the Dvir forms that are separated by ion-exchange chromatography. In the second form (Dvir-II) one Fe atom is missing, turning the siroheme-associated [4Fe-4S] cluster into a $[3 \mathrm{Fe}-4 \mathrm{~S}]$ one, and the authors attribute the difference in $\mathrm{pI}$ between the two Dvir forms to this fact. We have also observed by EPR that a $[3 \mathrm{Fe}-4 \mathrm{~S}]$ cluster is present in the slow form of $D$. vulgaris Dvir. However, we consider that this difference alone is 
A

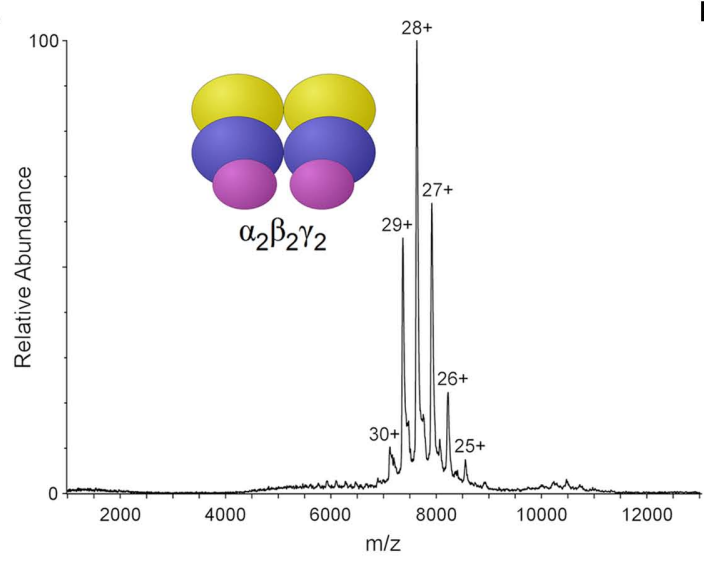

C

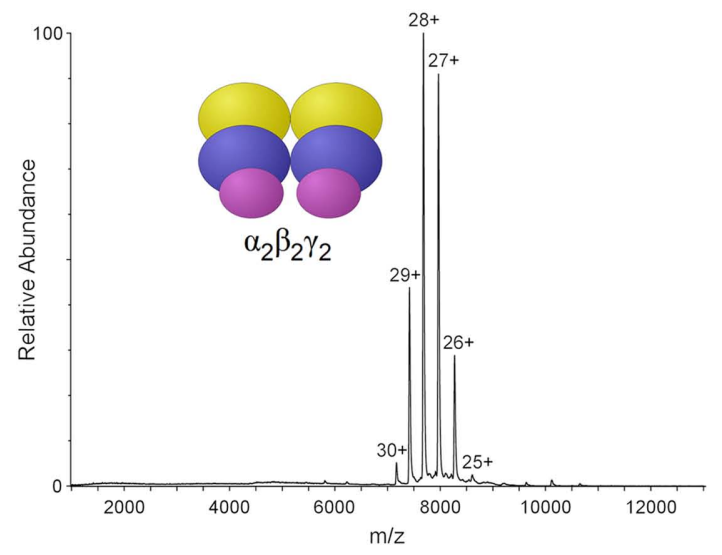

B

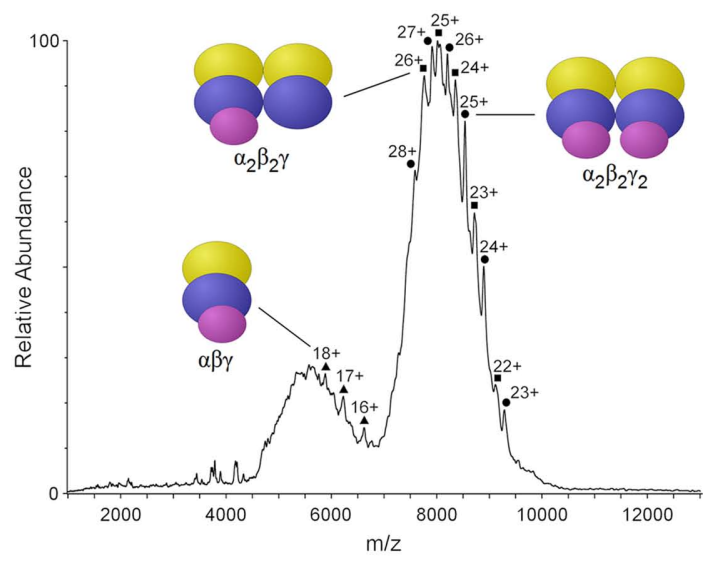

D

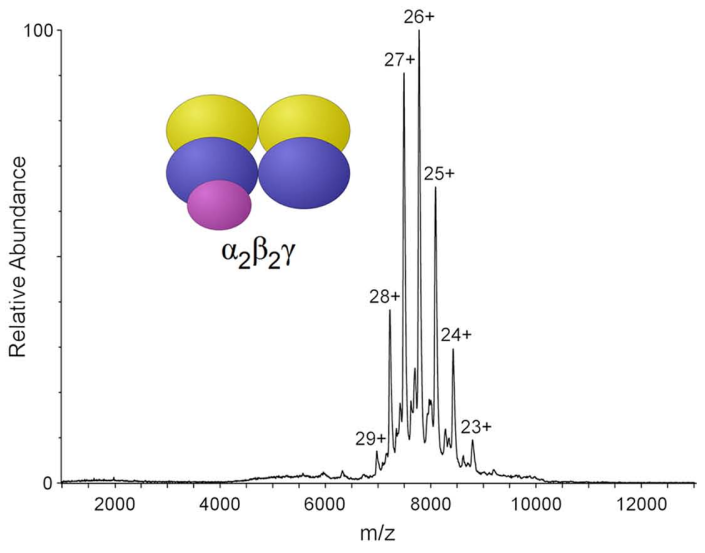

E

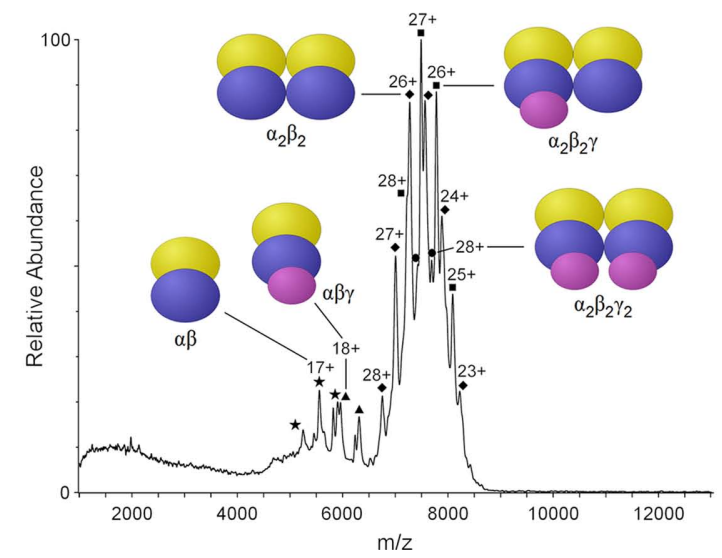

FIGURE 5 | Nano-ESI/MS spectra of the purified dSiRs bands after native gel electrophoresis; D. vulgaris Dvir (A) band 1, (B) band 2; D. norvegicum (C) band 1, (D) band 2, and (E) band 3. Schematic representation of the different chains as ovals colored as in Figure 1.

unlikely to explain the large difference in charge between the two Dvir forms, as the $\alpha_{2} \beta_{2}$ complex has a highly negative charge. Rather, it is likely that $D$. gigas Dvir-II separated by ion-chromatography is still a mixture of $\alpha_{2} \beta_{2} \gamma$ and $\alpha_{2} \beta_{2} \gamma_{2}$ forms, but the crystallization procedure has selected for the less flexible conformation in the $\alpha_{2} \beta_{2} \gamma_{2}$ form, which is observed in the crystal structure.

\section{SEARCH FOR THE DSIR ELECTRON DONOR}

The direct involvement of DsrC in the reduction of sulfite by DsrAB, as revealed by the D. vulgaris Dvir structure, led us to propose a mechanism for sulfite reduction in which reduced DsrC is a co-substrate of DsrAB, with oxidized DsrC (with a disulfide bond between the two C-terminal conserved Cys) being 

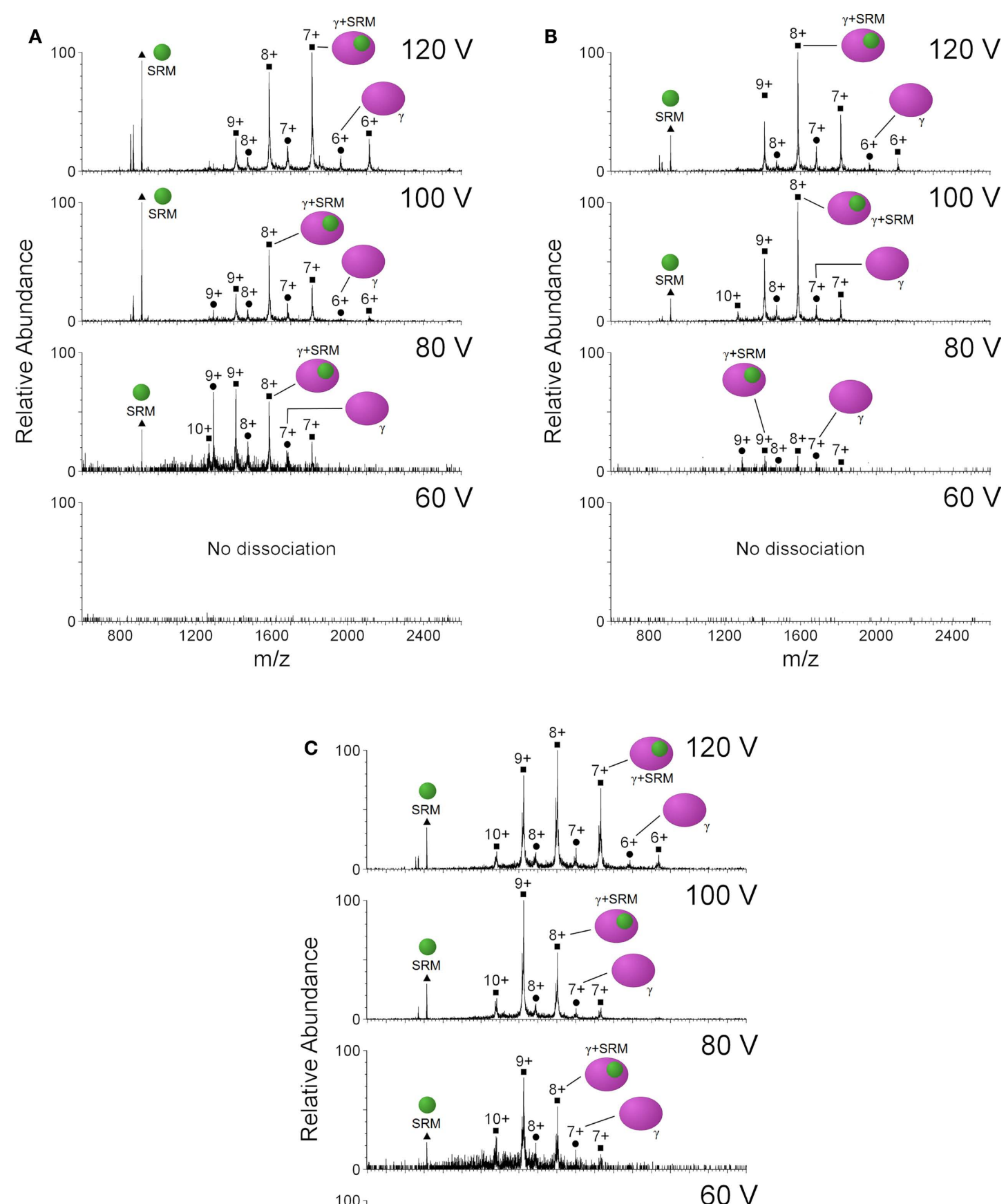

No dissociation
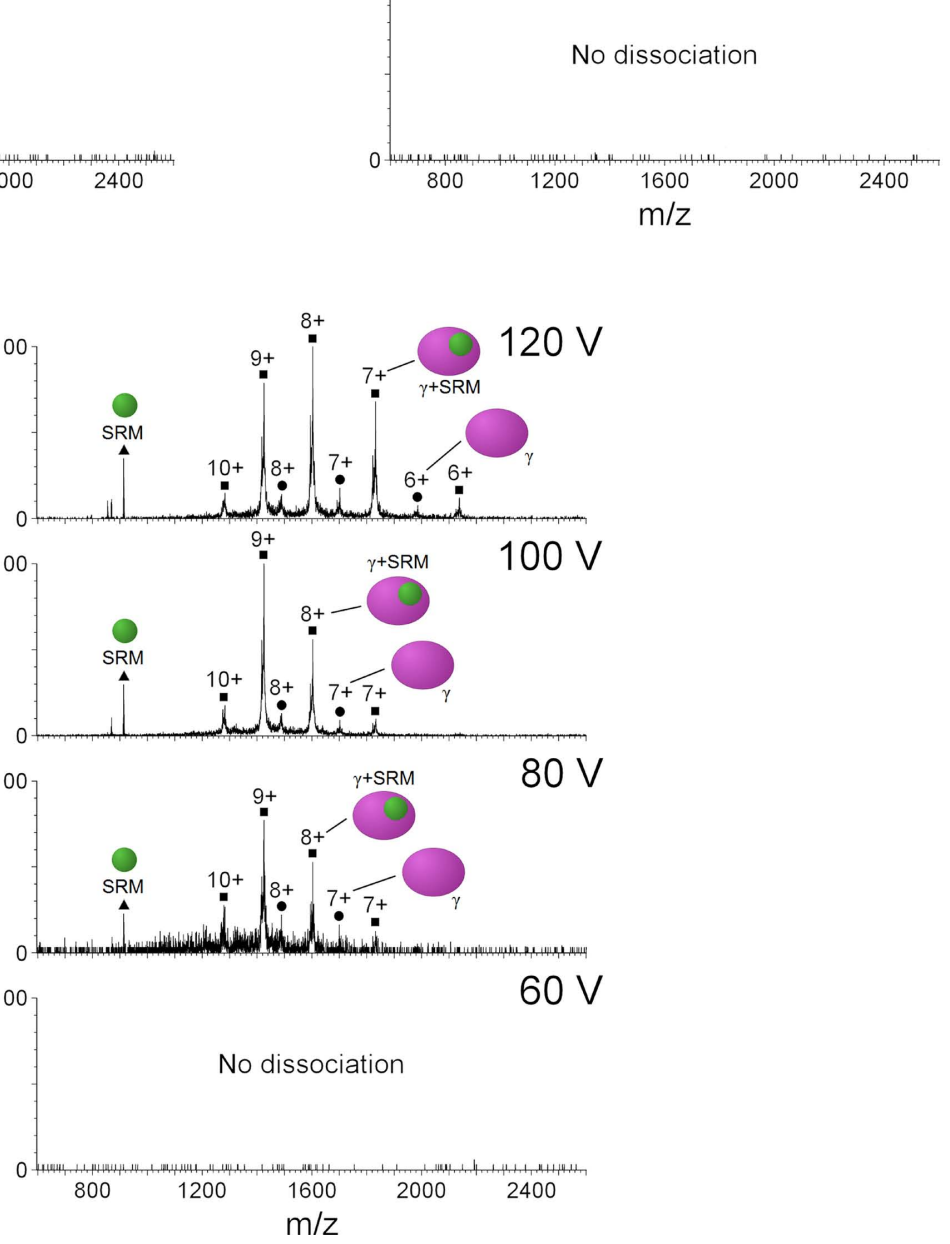

FIGURE 6 | Nano-ESI/MS spectra of (A) band 1 and (B) band 2 from dSiR $D$. norvegicum and for (C) band 1 from $D$. vulgaris, showing the presence of isolated DsrC and SRM and DsrC-SRM complex. Schematic representation of (DsrC) as magenta and siroheme (SRM) as green ovals.

formed as a product (Oliveira et al., 2008a). The oxidized DsrC is proposed to be reduced by the membrane-bound DsrMKJOP complex, with the result that two of the six electrons required for sulfite reduction probably originate from the quinone pool. This still leaves a requirement for another electron donor to deliver the remaining four electrons to $\mathrm{dSiR}$, but this donor has not yet 
Table 2 | Predicted and observed molecular weight of the different oligomeric forms of $D$. vulgaris Dvir and $D$. norvegicum Drub.

\begin{tabular}{|c|c|c|c|c|}
\hline & Predicted complex stoichiometry & Predicted cofactors & Theoretical MW (kDa) & Obtained MW (kDa) \\
\hline Dvir band 1 & $\alpha_{2} \beta_{2} \gamma_{2}$ & $2 \mathrm{SRM}+2 \mathrm{SRHC}+8[4 \mathrm{Fe}-4 \mathrm{~S}]$ & 213.3 & 213.8 \\
\hline \multirow[t]{2}{*}{ Dvir band 2} & $\alpha_{2} \beta_{2} \gamma_{2}$ & $2 \mathrm{SRM}+2 \mathrm{SRHC}+8[4 \mathrm{Fe}-4 \mathrm{~S}]$ & 213.3 & 213.4 \\
\hline & $\alpha \beta \gamma$ & $1 \mathrm{SRM}+1 \mathrm{SRHC}+4[4 \mathrm{Fe}-4 \mathrm{~S}]$ & 106.7 & 105.9 \\
\hline Drub band 1 & $\alpha_{2} \beta_{2} \gamma_{2}$ & $4 \mathrm{SRM}+8[4 \mathrm{Fe}-4 \mathrm{~S}]$ & 215.5 & 215.1 \\
\hline \multirow{4}{*}{ Drub band 3} & $\alpha_{2} \beta_{2} \gamma$ & $3 \mathrm{SRM}+8[4 \mathrm{Fe}-4 \mathrm{~S}]$ & 202.8 & 202.3 \\
\hline & $\alpha_{2} \beta_{2}$ & $2 \mathrm{SRM}+8[4 \mathrm{Fe}-4 \mathrm{~S}]$ & 190.0 & 189.1 \\
\hline & $\alpha \beta \gamma$ & $2 \mathrm{SRM}+4[4 \mathrm{Fe}-4 \mathrm{~S}]$ & 107.8 & 107.2 \\
\hline & $\alpha \beta$ & $1 \mathrm{SRM}+4[4 \mathrm{Fe}-4 \mathrm{~S}]$ & 95.0 & 94.5 \\
\hline
\end{tabular}

been identified. It is known that ferredoxin is the electron donor for the aSiRs and nitrite reductases. However, in dSir structures, a ferredoxin domain was incorporated in DsrA and DsrB during dSir evolution (Dahl et al., 1993; Dhillon et al., 2005). This incorporation suggests that the external electron donor may be a ferredoxin-reducing protein.

Using biochemical and biophysical techniques we have tried to examine two potential electron donors to dSiRs: PFOR, and ferredoxin-I. We first generated a model for the D. vulgaris Hildenborough PFOR based on the structure of PFOR from D. africanus (PDB code 1BOP; Chabriere et al., 2001), since the proteins share $69 \%$ sequence identity. The surface electrostatic potential was calculated for both D. vulgaris Dvir and PFOR structures, to detect possible interaction sites. On the $D$. vulgaris Dvir surface, a negatively charged region is observed in the ferredoxin domain of chain $\mathrm{B}$, which is a likely region for interaction with an electron donor. In contrast, an overall positive charge along the surface of the ferredoxin domain is observed in PFOR. Using modeling tools in Pymol, the PFOR ferredoxin domain can be placed in the vicinity of the $D$. vulgaris Dvir ferredoxin domain positioning the iron-sulfur clusters of the two domains at $\sim 15 \AA$ from each other. This suggests that electron transfer from the PFOR $[4 \mathrm{Fe}-4 \mathrm{~S}]$ cluster to the Dvir ferredoxin $[4 \mathrm{Fe}-4 \mathrm{~S}]$ cluster is possible, so PFOR looks like a plausible candidate electron donor.

We analyzed protein-protein interactions between the D. vulgaris Dvir and potential donors using surface plasmon resonance. However, we could detected no direct binding between immobilized Dvir and either PFOR or Fd-I. We cannot exclude that this technique may be hampered by the transient nature of the interaction between PFOR and Dvir. In addition to the direct protein-protein interaction assays, we also tested an activity-based assay for reduction of sulfite by Dvir with pyruvate/PFOR as electron donors. The assay was based on the measurement of sulfide production using the MB method. Again, we could detect no reduction of sulfite from pyruvate. These results do not suggest that PFOR or Fd-I may be physiological electron donors to dSiRs, or alternatively, the system may need other components to allow the enzyme to complete the catalytic cycle. Further work is necessary to elucidate the nature of the electron donor to dSiR.

\section{CONCLUSION}

In conclusion, the structure of a Drub determined herein shows that it is similar to the structure of Dvirs. The difference in spectral properties that led to its classification as a different protein is explained by the presence of both sirohydrochlorin and siroheme in Dvir, whereas only siroheme is present in Drub. Since the Drub sirohemes corresponding to the sirohydrochlorins are nonetheless not catalytic, there seems to be little justification for classifying Drub and Dvir as two different classes of dSiRs. The presence of two non-catalytic cofactors in the dSiRs has been confirmed in the four structures reported, where in the A. fulgidus $\mathrm{dSiR}$ and in the Drub structure reported herein these two cofactors are sirohemes, and in the D. vulgaris and D.gigas Dvirs they are sirohydrochlorins. The actual function of this cofactor is uncertain. It obviously results from the gene duplication event that gave rise to the homologous DsrA and DsrB subunits, but whereas in the aSiRs this event was followed by loss of this second cofactor (Crane and Getzoff, 1996), in dSiRs this cofactor has been retained. This may either mean that dSiRs are still at an intermediate stage of evolution, which will eventually lead to complete loss of the second cofactor, or that this cofactor has been kept because it is actually performing a valuable function. Since Fe is not required for this function, we tend to favor a structural role for the sirohydrochlorin/siroheme group, which probably serves to stabilize the whole molecule. From sequence and structural analysis we could not identify differences among the dSiRs that could explain why in some cases the Fe is lost, while in others it is retained. Elucidation of the $\mathrm{dSiR}$ cofactor insertion and maturation processes may in the future provide further clues to this issue. Schiffer et al. (2008) have also suggested that optimization of the catalytic siroheme site was achieved at the expense of the loss of catalytic activity at the second heme.

Using MS studies we established that purified Dvir and Drub are present in different oligomeric forms with two, one, or no DsrC molecules bound. The relative proportions of these species are likely to be highly dependent on the preparation, finally providing an explanation for the conflicting results in terms of cofactor content and spectroscopy results for these proteins. In addition, we obtained evidence for the fact that not all DsrC molecules in the DsrABC complexes have a covalent bond to the siroheme (as was recently confirmed by the D. gigas Dvir structures), which further 
supports the involvement of the DsrC penultimate Cys in the sulfite reduction mechanism. Our preliminary attempts to discover the physiological electron donor to dSir have proved unsuccessful, and future studies are necessary to elucidate this important question.

\section{ACKNOWLEDGMENTS}

This work was supported by research grant PTDC/QUIBIQ/100591/2008 to Inês A. C. Pereira and PTDC/BIAPRO/103718/2008 to Margarida Archer funded by Fundação para

\section{REFERENCES}

Akagi, J. M., Chan, M., and Adams, V. (1974). Observations on the bisulfite reductase (P582) isolated from Desulfotomaculum nigrificans. J. Bacteriol. 120, 240-244.

Arendsen, A. F., Verhagen, M. F., Wolbert, R. B., Pierik, A. J., Stams, A. J., Jetten, M. S., and Hagen, W. R. (1993). The dissimilatory sulfite reductase from Desulfosarcina variabilis is a desulforubidin containing uncoupled metalated sirohemes and $S=9 / 2$ iron-sulfur clusters. Biochemistry 32, 10323-10330.

Canfield, D. E., and Raiswell, R. (1999). The evolution of the sulfur cycle. Am. J. Sci. 299, 627-723.

Canfield, D. E., Rosing, M. T., and Bjerrum, C. (2006). Early anaerobic metabolisms. Philos. Trans. R. Soc. Lond. B Biol. Sci. 361, 1819-1834; discussion 1835-1836.

Chabriere, E., Vernede, X., Guigliarelli, B., Charon, M. H., Hatchikian, E. C., and Fontecilla-Camps, J.C. (2001). Crystal structure of the free radical intermediate of pyruvate:ferredoxin oxidoreductase, Science 294, 2559-2563.

Collaborative Computational Project, Number 4. (1994). The CCP4 suite: programs for protein crystallography. Acta Crystallogr. D Biol. Crystallogr. 50, 760-763.

Cort, J. R., Mariappan, S. V., Kim, C. Y., Park, M. S., Peat, T. S., Waldo, G. S., Terwilliger, T. C., and Kennedy, M. A. (2001). Solution structure of Pyrobaculum aerophilum DsrC, an archaeal homologue of the gamma subunit of dissimilatory sulfite reductase. Eur. J. Biochem. 268, 5842-5850.

Cort, J. R., Selan, U., Schulte, A., Grimm, F., Kennedy, M. A., and Dahl, C. (2008). Allochromatium vinosum DsrC: solution-state NMR structure, redox properties, and interaction with DsrEFH, a protein essential for purple sulfur bacterial sulfur oxidation. J. Mol. Biol. 382, 692-707.

Cowtan, K. (2006). The Buccaneer software for automated model building. 1. Tracing protein chains. Acta Crystallogr. D Biol. Crystallogr. 62, 1002-1011.

Crane, B. R., and Getzoff, E. D. (1996). The relationship between structure and function for the sulfite reductases. Curr. Opin. Struct. Biol. 6, 744-756.

Crane, B. R., Siegel, L. M., and Getzoff, E. D. (1995). Sulfite reductase structure at 1.6 A: evolution and catalysis for reduction of inorganic anions. Science 270, 59-67.

Dahl, C., Engels, S., Pott-Sperling, A. S., Schulte, A., Sander, J., Lubbe, Y., Deuster, O., and Brune, D. C. (2005). Novel genes of the dsr gene cluster and evidence for close interaction of Dsr proteins during sulfur oxidation in the phototrophic sulfur bacterium Allochromatium vinosum. J. Bacteriol. 187, 1392-1404.

Dahl, C., Kredich, N. M., Deutzmann, R., and Truper,H.G. (1993). Dissimilatory sulphite reductase from Archaeoglobus fulgidus: physico-chemical properties of the enzyme and cloning, sequencing and analysis of the reductase genes. $J$. Gen. Microbiol. 139, 1817-1828.

DeLano, W. L. (2002). The PyMOL Molecular Graphics System. San Carlos, CA: DeLano Scientific.

DerVartanian, D. V. (1994). Desulforubidin: dissimilatory, high-spin sulfite reductase of Desulfomicrobium species. Meth. Enzymol. 243, 270-276.

Dhillon, A., Goswami, S., Riley, M., Teske, A., and Sogin, M. (2005). Domain evolution and functional diversification of sulfite reductases. Astrobiology 5, 18-29.

Emsley, P., and Cowtan, K. (2004). Coot: model-building tools for molecular graphics. Acta Crystallogr. D Biol. Crystallogr. 60, 2126-2132.

Fogo, J. K., and Milton, P. (1949). Spectrophotometric determination of hydrogen sulfide. Anal. Chem. 21, 732-734.

Hatchikian, E. C. (1994). Desulfofuscidin: dissimilatory, high-spin sulfite reductase of thermophilic, sulfate-reducing bacteria. Meth. Enzymol.243, 276-295.

Hatchikian, E. C., and Zeikus, J. G. (1983). Characterization of a new type of dissimilatory sulfite reductase present in Thermodesulfobacterium commune. J. Bacteriol. 153, 1211-1220.

Hsieh, Y.C., Liu, M.Y., Wang, V.C., Chiang, Y. L., Liu, E. H., Wu, W. G., Chan, S. I., and Chen, C. J. (2010). Structural

a Ciência e Tecnologia (FCT, MCTES, Portugal); and by a Science Foundation Ireland Investigator grant (07/IN.1/B975) to Amir R. Khan, Edward Franklin and Tânia F. Oliveira. FCT is acknowledged for the fellowship to Tânia F. Oliveira (SFRH/BD/29519/2006) and ESRF for financial and technical support for X-ray diffraction data collection. We thank Dr. Pedro Matias for help in refinement and fruitful discussions. We acknowledge Dr. Chun-Jung Chen (Taiwan) for providing us the coordinates of D. gigas Dvir with the retracted DsrC C-terminal arm.

insights into the enzyme catalysis from comparison of three forms of dissimilatory sulphite reductase from Desulfovibrio gigas. Mol. Microbiol.78, 1101-1116.

Ikeuchi, Y., Shigi, N., Kato, J., Nishimura, A., and Suzuki, T. (2006). Mechanistic insights into multiple sulfur mediators sulfur relay by involved in thiouridine biosynthesis at tRNA wobble positions. Mol. Cell 21, 97-108.

Klein, M., Friedrich, M., Roger, A. J. Hugenholtz, P., Fishbain, S., Abicht, H., Blackall, L. L., Stahl, D. A., and Wagner, M. (2001). Multiple lateral transfers of dissimilatory sulfite reductase genes between major lineages of sulfatereducing prokaryotes. J. Bacteriol. 183, 6028-6035.

Krissinel, E., and Henrick, K. (2004). Secondary-structure matching (SSM), a new tool for fast protein structure alignment in three dimensions. Acta Crystallogr. D Biol. Crystallogr. 60 2256-2268.

Laskowski, R.A., MacArthur, M.W., Moss, D. S., and Thornton, J. M. (1993). PROCHECK: a program to check the stereochemical quality of protein structures. J. Appl. Crystallogr. 26 283-291.

Lee, J. P., and Peck, H. D. (1971). Purification of the enzyme reducing bisulfite to trithionate from Desulfovibrio gigas and its identification as desulfoviridin. Biochem. Biophys. Res. Commun. 45, 583-589.

Lee, J. P., Yi, C.-S., LeGall, J., and Peck, H. D. (1973). Isolation of a new pigment, desulforubidin, from Desulfovibrio desulfuricans (Norway strain) and its role in sulfite reduction. J. Bacteriol. 115, 453-455.

Leslie, A. G. W. (1992). Joint CCP4+ESFEAMBC Newsletter on Protein Crystallography 26.

Loy, A., Duller, S., and Wagner, M. (2007) "Evolution and ecology of microbes dissimilating sulfur compounds: insights from siroheme sulfite reductases," in Microbial Sulfur Metabolism, eds C. Dahl and C. Friedrich (Berlin: Springer), 46-59.

Mander, G. J., Weiss, M. S., Hedderich, R. Kahnt, J., Ermler, U., and Warkentin, E. (2005). X-ray structure of the gamma-subunit of a dissimilatory sulfite reductase: fixed and flexible C-terminal arms. FEBS Lett. 579, 4600-4604.

Marritt, S. J., and Hagen, W. F. (1996). Dissimilatory sulfite reductase revisited. The desulfoviridin molecule does contain 20 iron ions, extensively demetallated siroheme, and an $\mathrm{S}=9 / 2$ iron-sulfur cluster. Eur. J. Biochem. 238, 724-727.

Matthews, B. W. (1968). Solvent content of protein crystals. J. Mol. Biol. 33, 491-497.

McCoy, A. J., Grosse-Kunstleve, R. W., Adams, P. D., Winn, M. D., Storoni, L. C., and Read, R. J. (2007). Phaser crystallographic software. J. Appl. Crystallogr. 40, 658-674.

Molitor, M., Dahl, C., Molitor, I., Schafer, U., Speich, N., Huber, R., Deutzmann, R., and Truper,H. G. (1998). A dissimilatory siroheme-sulfite-reductase-type protein from the hyperthermophilic archaeon Pyrobaculum islandicum. Microbiology 144(Pt 2), 529-541.

Moura, I., LeGall, J., Lino, A. R., Peck, H. D., Fauque, G., Xavier, A. V., DerVartanian, D. V., Moura, J. J. G., and Huynh, B. H. (1988). Characterization of two dissimilatory sulfite reductases (desulforubidin and desulfoviridin) from the sulfate-reducing bacteria. Mössbauer and EPR Studies. J. Am. Chem. Soc. 110, 1075-1082.

Murshudov, G. N., Vagin, A. A., and Dodson, E. J. (1997). Refinement of macromolecular structures by the maximum-likelihood method. Acto Crystallogr. D Biol. Crystallogr. 53, 240-255.

Numata, T., Fukai, S., Ikeuchi, Y., Suzuki, T., and Nureki, O. (2006). Structural basis for sulfur relay to RNA mediated by heterohexameric TusBCD complex. Structure 14, 357-366.

Oliveira, T. F., Vonrhein, C., Matias, P. M., Venceslau, S. S., Pereira, I. A., and Archer, M. (2008a). The crystal structure of Desulfovibrio vulgaris dissimilatory sulfite reductase bound to DsrC provides novel insights into the mechanism of sulfate respiration. J. Biol. Chem. 283, 34141-34149. 
Oliveira, T. F., Vonrhein, C., Matias, P. M., Venceslau, S. S., Pereira, I. A., and Archer, M. (2008b). Purification, crystallization and preliminary crystallographic analysis of a dissimilatory DsrAB sulfite reductase in complex with DsrC. J. Struct. Biol. 164, 236-239.

Parey, K., Warkentin, E., Kroneck, P. M., and Ermler, U. (2010). Reaction cycle of the dissimilatory sulfite reductase from Archaeoglobus fulgidus. Biochemistry 49, 8912-8921.

Peck, H. D. Jr., and LeGall, J. (1982). Biochemistry of dissimilatory sulphate reduction. Philos. Trans. R. Soc. Lond. B Biol. Sci. 298, 443-466.

Pereira, P. M., Teixeira, M., Xavier, A. V., Louro, R. O., and Pereira, I.A.C. (2006). The Tmc complex from Desulfovibrio vulgaris Hildenborough is involved in transmembrane electron transfer from periplasmic hydrogen oxidation. Biochemistry 45, 10359-10367.

Pierik, A. J., Duyvis, M. G., van Helvoort, J. M., Wolbert, R. B., and Hagen, W. R. (1992). The third subunit of desulfoviridin-type dissimilatory sulfite reductases. Eur. J. Biochem. 205, 111-115.

Pierik, A. J., and Hagen, W. R. (1991). $S=9 / 2$ EPR signals are evidence against coupling between the siroheme and the Fe/S cluster prosthetic groups in Desulfovibrio vulgaris (Hildenborough) dissimilatory sulfite reductase. Eur. J. Biochem. 195, 505-516.
Pires, R. H., Venceslau, S. S., Morais, F., Teixeira, M., Xavier, A. V., and Pereira, I. A. C. (2006). Characterization of the Desulfovibrio desulfuricans ATCC 27774 DsrMKJOP complex - a membrane-bound redox complex involved in sulfate respiration. Biochemistry 45 , 249-262.

Rabus, R., Hansen, T., and Widdel, F. (2007). "Dissimilatory sulfate- and sulfur-reducing prokaryotes," in The Prokaryotes, ed. M. E. A. Dworkin (New York: Springer-Verlag), 659-768.

Schiffer, A., Parey, K., Warkentin, E., Diederichs, K., Huber, H., Stetter, K. O., Kroneck, P. M., and Ermler, U. (2008). Structure of the dissimilatory sulfite reductase from the hyperthermophilic archaeon Archaeoglobus fulgidus. J. Mol. Biol. 379, 1063-1074.

Schnell, R., Sandalova, T., Hellman, U., Lindqvist, Y., and Schneider, G. (2005). Siroheme- and [Fe4-S4]-dependent NirA from Mycobacterium tuberculosis is a sulfite reductase with a covalent Cys-Tyr bond in the active site. J. Biol. Chem. 280, 27319-27328.

Seki, Y., Kobayashi, K., and Ishimoto, M. (1979). Biochemical studies on sulfate-reducing bacteria. XV. Separation and comparison of two forms of desulfoviridin. J. Biochem. 85, 705-711.

Steuber, J., Arendsen, A. F., Hagen, W. R., and Kroneck, P. M. (1995). Molecular properties of the dissimilatory sulfite reductase from Desulfovibrio desulfuricans (Essex) and comparison with the enzyme from Desulfovibrio vulgaris (Hildenborough). Eur. J. Biochem. 233, 873-879.

Steuber, J., Cypionka, H., and Kroneck, P. M.H. (1994). Mechanism of dissimilatory sulfite reduction by Desulfovibrio desulfuricans - purification of a membrane-bound sulfite reductase and coupling with cytochrome C(3) and hydrogenase. Arch. Microbiol. 162, 255-260.

Swamy, U., Wang, M., Tripathy, J. N., Kim, S. K., Hirasawa, M., Knaff, D. B., and Allen, J. P. (2005). Structure of spinach nitrite reductase: implications for multi-electron reactions by the ironsulfur:siroheme cofactor. Biochemistry 44, 16054-16063.

Wagner, M., Roger, A. J., Flax, J. L. Brusseau, G. A., and Stahl, D. A. (1998). Phylogeny of dissimilatory sulfite reductases supports an early origin of sulfate respiration. $J$. Bacteriol. 180, 2975-2982.

Weiss, M. S., Mander, G., Hedderich, R., Diederichs, K., Ermler, U., and Warkentin, E. (2004). Determination of a novel structure by a combination of long-wavelength sulfur phasing and radiation-damage-induced phasing Acta Crystallogr. D Biol. Crystallogr. 60, 686-695.

Wolfe, B. M., Lui, S. M., and Cowan, J. A. (1994). Desulfoviridin, a multimeric-dissimilatory sulfite reductase from Desulfovibrio vulgaris (Hildenborough). Purification, characterization, kinetics and EPR studies. Eur. J. Biochem. 223, 79-89.

Zverlov, V., Klein, M., Lucker, S., Friedrich, M.W., Kellermann, J., Stahl, D. A., Loy, A., and Wagner, M. (2005). Latera gene transfer of dissimilatory (bi) sulfite reductase revisited. J. Bacteriol. 187, 2203-2208.

Conflict of Interest Statement: The authors declare that the research was conducted in the absence of any commercial or financial relationships that could be construed as a potential conflict of interest.

Received: 09 February 2011; paper pending published: 25 February 2011; accepted: 28 March 2011; published online: 13 April 2011.

Citation: Oliveira TF, Franklin E, Afonso JP, Khan AR, Oldham NJ, Pereira IAC and Archer M (2011) Structural insights into dissimilatory sulfite reductases: structure of desulforubidin from Desulfomicrobium norvegicum. Front. Microbio. 2:71. doi: 10.3389/fmicb.2011.00071

This article was submitted to Frontiers in Microbial Physiology and Metabolism, a specialty of Frontiers in Microbiology. Copyright (c) 2011 Oliveira, Franklin, Afonso, Khan, Oldham, Pereira and Archer. This is an open-access article subject to a non-exclusive license between the authors and Frontiers Media SA, which permits use, distribution and reproduction in other forums, provided the original authors and source are credited and other Frontiers conditions are complied with. 